\title{
Suppression of Elevated Temperature Hydraulic Fluid and JP-8 Spray Flames
}

\author{
I. VÁZOUEZ, W. GROSSHANDLER, W. RINKINEN and M. P. GLOVER \\ Building and Fire Research Laboratory \\ National Institute of Standards and Technology \\ Gaithersburg, Maryland 20899, USA \\ C. PRESSER \\ Chemical Science and Technology Laboratory \\ National Institute of Standards and Technology \\ Gaithersburg, Maryland 20899, USA
}

\begin{abstract}
A coaxial turbulent spray burner was used to determine the suppression characteristics of twelve different fire fighting agents in elevated temperature hydraulic fluid and jet fuel (JP-8) spray flames. The effectiveness of the gaseous agents, being considered as alternatives to halon 1301, was compared based upon the mass required for suppression and the equivalent storage volume, normalized by the amount of halon 1301 required to suppress the flame. The elevated temperature results were compared to measurements previously obtained with the incoming air and JP-8 at ambient temperature. No statistically significant difference in relative agent performance was found between the heated hydraulic flame and the previous JP-8 experiments. There was a trend toward higher agent concentrations when the fuel was JP-8 and the temperature of the incoming reactants was $150^{\circ} \mathrm{C}$. In all three experiments, the halon 1301 required the least mass to extinguish the flame, followed by nitrogen. The rest of the alternative fluorinated agents considered required between 1.2 and 2.4 times more mass to suppress the various flames.
\end{abstract}

KEYWORDS: aircraft engines; aircraft fires; fire suppression; halon 1301; turbulent combustion

\section{INTRODUCTION}

Halon 1301, or trifluorobromomethane $\left(\mathrm{CF}_{3} \mathrm{Br}\right)$, is used as a fire extinguishing agent for protecting aircraft engine nacelles because of its many positive attributes (liquid at room temperature and high pressure, gas at atmospheric conditions, low toxicity, strong flame inhibition). However, because of its undesirable high reactivity with stratospheric ozone, the 
international community has agreed, under the Montreal Protocol, to eliminate its manufacture starting in 1994 [1]. An alternative chemical compound is needed to perform the same function as halon 1301 without creating unacceptable safety, environmental or systems compatibility problems. The work presented here is part of a larger effort focused on finding an alternative to halon 1301 for in-flight aircraft fire protection [2,3,7].

The engine nacelle encases the jet engine compressor, combustor and turbine. A nacelle fire is typically a turbulent diffusion flame stabilized behind an obstruction in a moderately high speed air flow. Jet fuel or hydraulic fluid, either as a spray or pre-vaporized, is the most likely source for the fire. Extinguishment occurs when a critical level of agent is mixed with the air upstream, and is transported to the flame where it is entrained into the primary reaction zone. The process is affected by a number of parameters including velocity of the air flow, type and quantity of fuel, system temperature, and agent properties and concentration.

A recently completed study [4] investigated the performance of over a dozen fluorocarbons (FCs), hydrofluorocarbons (HFCs) and hydrochlorofluorocarbons (HCFCs) proposed as alternatives to halon 1301. A coaxial turbulent spray burner was used to simulate an idealized engine nacelle fire, with JP-8 and the air at ambient temperature. However, temperatures as high as $150^{\circ} \mathrm{C}$ are common in engine nacelles. The hydraulic lines located in the nacelle are exposed to this high temperature and represent an additional potential source of fire. Therefore, it was necessary to investigate the effect of higher temperature and fuel type on the relative agent performance.

The work presented in this paper examines the following specific compounds to determine the impact of changing the fuel type and increasing the temperature of the fuel and reactants on relative flame inhibition: halon $1301\left(\mathrm{CF}_{3} \mathrm{Br}\right)$; nitrogen $\left(\mathrm{N}_{2}\right)$; $\mathrm{FCs} 116\left(\mathrm{C}_{2} \mathrm{~F}_{6}\right), 218\left(\mathrm{C}_{3} \mathrm{~F}_{8}\right)$, $318\left(\right.$ cyclo- $\left.\mathrm{C}_{4} \mathrm{~F}_{8}\right)$ and 31-10 $\left(\mathrm{C}_{4} \mathrm{~F}_{10}\right)$; HFCs $125\left(\mathrm{C}_{2} \mathrm{HF}_{5}\right), 134 \mathrm{a}\left(\mathrm{C}_{2} \mathrm{H}_{2} \mathrm{~F}_{4}\right), 227\left(\mathrm{C}_{3} \mathrm{HF}_{7}\right), 236 \mathrm{fa}$ $\left(\mathrm{C}_{3} \mathrm{H}_{2} \mathrm{~F}_{6}\right)$, and a $32 / 125$ mixture $\left(\mathrm{CH}_{2} \mathrm{~F}_{2} / \mathrm{C}_{2} \mathrm{HF}_{5}\right)$; and $\mathrm{HCFCs} 22\left(\mathrm{CHF}_{2} \mathrm{Cl}\right)$ and 124 $\left(\mathrm{C}_{2} \mathrm{HF}_{4} \mathrm{Cl}\right)$.

\section{EXPERIMENTAL APPARATUS}

The apparatus consisted of two major components: a coaxial turbulent spray burner, and an agent injection mechanism. The burner included a $50 \mathrm{~mm}$ (O.D.) diameter stainless steel tube with a concentric $6.4 \mathrm{~mm}$ (O.D.) diameter fuel supply pipe on the centerline. Figure 1 shows a cross-sectional view of the burner. The fuel was injected through a pressure-jet nozzle that formed a $45^{\circ}$ solid cone spray. Hot air co-flowed around the nozzle in an annular passage. A $35 \mathrm{~mm}$ disc was attached to the body of the nozzle in order to stabilize the flame. A 65 $\mathrm{mm}$ (O.D.) diameter pyrex tube supported on a Teflon ring extended $75 \mathrm{~mm}$ beyond the nozzle exit plane to permit observation of the flame under confined conditions and the suppression event.

The air was supplied by a high capacity compressor at about $800 \mathrm{kPa}$ and heated with a 60 $\mathrm{kW}$ electric heater up to $150^{\circ} \mathrm{C}$. This hot air preheated the fuel and agent from the fuel inlet point and agent injection point up to the pressure-jet nozzle. The air flow was monitored by a calibrated sonic orifice. A thermocouple was placed downstream of the metering orifice and $1.1 \mathrm{~m}$ upstream of the nozzle to measure the incoming air temperature. 


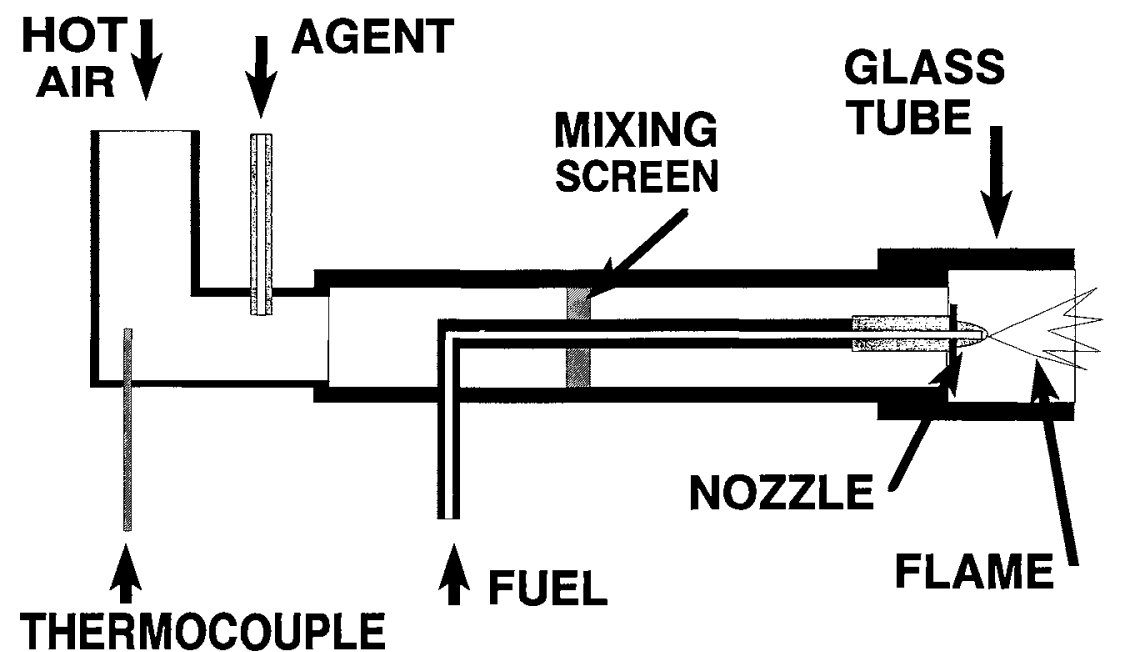

FIGURE 1 Cross-sectional view of the turbulent jet burner

The fuel, either JP-8 (MIL-T-83133D) or hydraulic fluid (MIL-H-83282C), was stored in an 18 liter tank and delivered to the burner with a gear pump at pressures controllable up to 1.03 MPa-g. The fuel nozzle was nominally rated at $0.46 \mathrm{ml} / \mathrm{s}$ for high temperture JP-8 fuel at this pressure. The properties for both fuels used in the experiments are shown in Table 1.

TABLE 1 Fuel Properties

\begin{tabular}{c|c|c}
\hline PARAMETER & Jet Fuel (JP-8) & Hydraulic Fluid \\
\hline Viscosity, $\mathrm{m}^{2} / \mathrm{s}$ & $8.0 \times 10^{-6}\left(@-20^{\circ} \mathrm{C}\right)$ & $3.45 \times 10^{-6}\left(@ 100^{\circ} \mathrm{C}\right)$ \\
$\begin{array}{c}\text { Density @ } 20^{\circ} \mathrm{C}, \\
\text { grams } / \mathrm{ml}\end{array}$ & $0.81 \pm 0.01$ & $0.82 \pm 0.01$ \\
Flash Point, ${ }^{\circ} \mathrm{C}$ & 38 & 205 \\
Heat of Combustion ${ }^{\mathrm{a}}$, & 46.5 & 45.1 \\
$\mathrm{MJ} / \mathrm{kg}$ & & $\mathrm{b}$ \\
Distillation, & $205-300^{\circ} \mathrm{C}$ & \\
Boiling Point & & \\
\hline
\end{tabular}

"Gascoyne Laboratories, 1993

b Not available 
The injection mechanism, shown in Figure 2, consisted of the agent supply bottle connected to a stainless steel storage vessel through a metering valve, and to the burner through a computer controlled solenoid valve. The volume of the storage vessel was $1040 \pm 10 \mathrm{ml}$ and the agent pressure was maintained between 121 and $298 \mathrm{kPa}-\mathrm{g}$. The agent temperature and pressure in the storage vessel were measured with a type- $\mathrm{K}$ thermocouple and a pressure transducer located upstream of the solenoid valve. At the desired time the computercontrolled solenoid valve opened and the gaseous agent was injected impulsively into the preheated air $0.5 \mathrm{~m}$ upstream of the fuel inlet through two $6.4 \mathrm{~mm}$ (O.D.) tubes offset from the burner centerline. The hot air carried the agent downstream to the flame. Screens were placed downstream of the agent injection point to enhance the uniform mixing of the agent into the air prior to the agent reaching the flame.

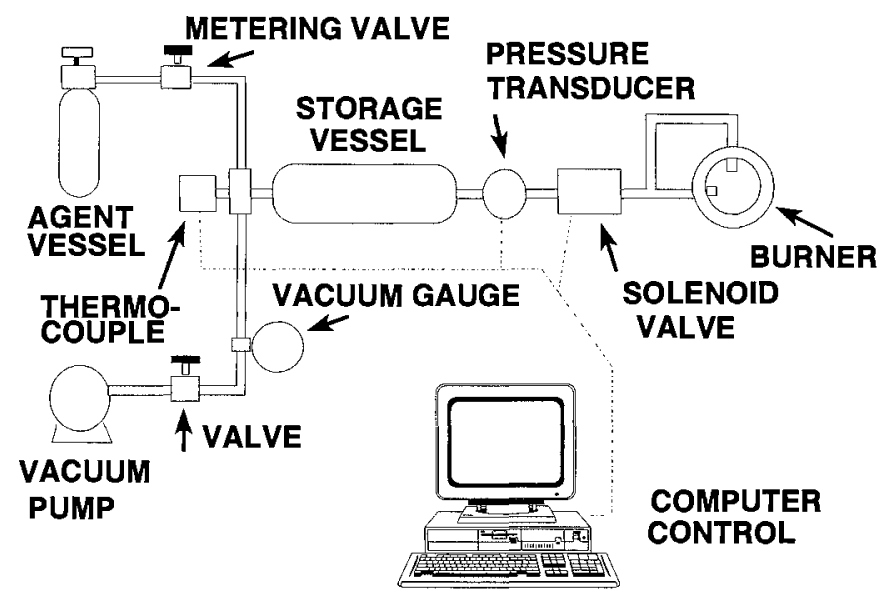

FIGURE 2 Gaseous agent injection mechanism schematic.

\section{EXPERIMENTAL PROCEDURE}

The flame was ignited using a propane torch, the flows were adjusted to their appropriate values, and the incoming air temperature was allowed to equilibrate for several minutes before beginning an experiment. The flame attached itself to the stabilizing disk with the plume located within the glass tube passage. The JP-8 flame was luminous and approximately $0.1 \mathrm{~m}$ in length at the operating air flow rate. A moderate amount of soot formed on the nozzle face in a matter of minutes. The hydraulic-fluid flame was blue with little evidence of soot being formed under these conditions.

The high-temperature air flow preheated the agent and fuel while in the $1.1 \mathrm{~m}$ burner section upstream of the nozzle. Because of the lower fuel density at high temperature, the fuel 
pressure was increased to maintain the same fuel flow rate as the previous room temperature experiments [4]. However, due to system constraints the fuel flow obtained for the high air temperature JP-8 flame was only $90 \%$ of the ambient air temperature JP- 8 test.

The hydraulic fluid flow rates and temperature were adjusted according to flame stability. The fuel temperature and the air-to-fuel ratio were varied until flame stability was obtained. This was achieved at an air temperature of $120{ }^{\circ} \mathrm{C}$, an air flow rate of $30.4 \mathrm{~g} / \mathrm{s}$ and the hydraulic fluid flow rate of $0.65 \mathrm{ml} / \mathrm{s}$ (fuel pressure $=0.90 \mathrm{MPa}-\mathrm{g}$ ). No ambient temperature tests were performed using hydraulic fluid since a flame could not be stabilized.

The fuel flow was calibrated at the actual operating pressures and temperatures for the two fuels. The operational parameters used in this and the previous study are shown in Table 2. Uncertainties were determined using Taylor and Kuyatt [5], having an approximate level of confidence of $95 \%$.

TABLE 2 Operational conditions for the experiment

\begin{tabular}{|c|c|c|c|}
\hline PARAMETER & JP-8 (AMBIENT) & JP-8 (HOT) & $\begin{array}{l}\text { HYDRAULIC } \\
\text { FLUID (HOT) }\end{array}$ \\
\hline Air Temperature & $19-25^{\circ} \mathrm{C}$ & $146-153^{\circ} \mathrm{C}$ & $118-123^{\circ} \mathrm{C}$ \\
\hline Air Pressure & atmospheric & atmospheric & atmospheric \\
\hline Air Flow & $33 \pm 1 \mathrm{~g} / \mathrm{s}$ & $33 \pm 1 \mathrm{~g} / \mathrm{s}$ & $30 \pm 1 \mathrm{~g} / \mathrm{s}$ \\
\hline $\begin{array}{l}\text { Nominal Air } \\
\text { Velocity }\end{array}$ & $14 \mathrm{~m} / \mathrm{s}$ & $20 \mathrm{~m} / \mathrm{s}$ & $18 \mathrm{~m} / \mathrm{s}$ \\
\hline Fuel Temperature & $19-25^{\circ} \mathrm{C}$ & $75^{\circ} \mathrm{C}^{*}$ & $60^{\circ} \mathrm{C}^{*}$ \\
\hline Fuel Pressure & $687 \pm 10 \mathrm{kPa}-\mathrm{g}$ & $1034 \pm 10 \mathrm{kPa}-\mathrm{g}$ & $896 \pm 10 \mathrm{kPa}-\mathrm{g}$ \\
\hline Fuel Flow & $0.51 \pm 0.05 \mathrm{ml} / \mathrm{s}$ & $0.46 \pm .05 \mathrm{ml} / \mathrm{s}$ & $0.65 \pm .05 \mathrm{ml} / \mathrm{s}$ \\
\hline Thermal Output & $18 \pm 2 \mathrm{~kW}$ & $16 \pm 2 \mathrm{~kW}$ & $23 \pm 2 \mathrm{~kW}$ \\
\hline $\begin{array}{c}\text { Nominal } \\
\text { Equivalence Ratio }\end{array}$ & 0.17 & 0.15 & 0.23 \\
\hline $\begin{array}{l}\text { Initial Agent } \\
\text { Temperature }\end{array}$ & $20-25^{\circ} \mathrm{C}$ & $20-25^{\circ} \mathrm{C}$ & $20-25^{\circ} \mathrm{C}$ \\
\hline $\begin{array}{l}\text { Initial Agent } \\
\text { Pressure }\end{array}$ & $20-60 \mathrm{kPa}$ & $20-60 \mathrm{kPa}$ & $20-60 \mathrm{kPa}$ \\
\hline Injection Interval & $75 \pm 10 \mathrm{~ms}$ & $75 \pm 10 \mathrm{~ms}$ & $75 \pm 10 \mathrm{~ms}$ \\
\hline
\end{tabular}

* Estimated

The agent injection process began by evacuating and flushing the storage vessel several times with the agent under investigation in order to purge contaminating gases from the system. 
The pressure in the vessel was adjusted with the solenoid valve closed using the inlet metering valve. Initially, a pressure was chosen which was expected to be insufficient to extinguish the flame. The computer control/data acquisition system was initiated and the response of the flame to the injection process was observed. If the flame was not extinguished, the pressure was increased and the experiment was repeated. Eventually a pressure was found which provided enough agent to suppress the flame. This procedure was normally repeated four times for each agent.

The amount of injected agent was controlled by varying the initial pressure and the amount of time the valve was opened. The injection period was set nominally for $75 \mathrm{~ms}$ in all the experiments presented in this paper. The amount of gaseous agent injected was determined from the difference between the initial and final temperature and pressures in the storage vessel using the Redlich-Kwong equation of state [6].

Calibration of the injection system and a discussion of the various parameters which affect flame suppression at room temperature in the turbulent spray burner are discussed elsewhere $[4,7]$. The mass delivered to the burner, the injection time interval, and the average flow of agent were calculated using the method described by Grosshandler et al. [4].

\section{EXPERIMENTAL RESULTS}

The results for the high temperature JP-8 and hydraulic fluid experiments are summarized in Table 3. This table shows the average mass of agent required to suppress the high temperature JP-8 and hydraulic fluid flames. The ambient temperature JP-8 results from the previous study [4] are included for comparison purposes. The uncertainties for the mass and mass flow of agent were calculated using Taylor and Kuyatt [5] and correspond to $\pm 5 \%$, having an approximate level of confidence of $95 \%$.

As indicated in Table 3, no difference was found between the amount of halon 1301 required to extinguish the hydraulic fluid and the ambient temperature air JP-8 flames. In contrast, the hydraulic fluid flame required $23 \%$ less nitrogen for flame extinguishment than the ambient temperature air JP-8 flame. FC-318 was at the other extreme, requiring $11 \%$ more agent for the hydraulic fluid flame than the amount measured in the cooler JP-8 flame. FC31-10 was not tested with the hydraulic fluid. For the remaining agents, the mass required to extinguish the hydraulic fluid flame was comparable to the mass required to extinguish the ambient air JP-8 flame (see Table 3) within a difference greater than the uncertainty of the measurements $( \pm 5 \%)$.

The air and fuel temperature had a significant impact on the amount of halon 1301 required to suppress the JP-8 spray flame. The nitrogen mass required to suppress the flame also increased at elevated air and fuel temperatures to a lesser degree. The majority of the agents required more mass to extinguish the higher temperature JP- 8 flame, with an average increase of $0.04 \mathrm{~g}$ (see Table 3). This trend is not unanticipated since one would expect a higher enthalpy flame to be more stable, implying that a larger amount of agent would be necessary for a successful suppression.

A direct comparison of agent performance based only on fuel type and temperature is not possible at this time because the fuel type and temperature could not be varied independently. 
TABLE 3 Mass of agent required to suppress JP-8 and hydraulic fluid spray flames.

\begin{tabular}{c|c|c|c}
\hline Agent & $\begin{array}{c}\text { JP-8, } \mathrm{T}_{\text {amb }} \\
\text { (grams) }\end{array}$ & $\begin{array}{c}\text { JP-8 (Hot) } \\
\text { (grams) }\end{array}$ & $\begin{array}{c}\text { Hydr. Fluid (Hot) } \\
\text { (grams) }\end{array}$ \\
\hline Halon 1301 & 0.44 & 0.53 & 0.44 \\
Nitrogen & 0.58 & 0.63 & 0.42 \\
HCFC-22 & 0.65 & 0.70 & 0.70 \\
HFC-125 & 0.73 & 0.77 & 0.78 \\
HCFC-124 & 0.74 & 0.75 & 0.70 \\
FC-116 & 0.75 & 0.74 & 0.73 \\
HFC-134A & 0.76 & 0.78 & 0.79 \\
HFC-236FA & 0.78 & 0.84 & 0.78 \\
HFC-227 & 0.80 & 0.81 & 0.82 \\
HFC-32/125 & 0.81 & 0.89 & 0.82 \\
FC-218 & 0.89 & 0.87 & 0.86 \\
FC-318 & 0.97 & 0.99 & 1.08 \\
FC-31-10 & 1.00 & 1.02 & $\mathrm{a}$ \\
\hline
\end{tabular}

a Not tested

These constraints disallowed equal experimental conditions between the three experimental series. Nevertheless, the information obtained from each series of experiments (JP- 8 at ambient temperature, hot JP-8 and hot hydraulic fluid) was sufficient to evaluate the agent relative performance among themselves under indentical experimental conditions.

When the agents are ranked according to the mass required to inhibit the flame, the order does not change by more than plus or minus one position for the three series of experiments. The exception is HFC-125, which drops two positions in both of the high temperature tests.

Expressing the results in terms of the flame suppression number (FSN) is a convenient way to compare the performance of the different agents in the three series of experiments. The FSN is defined as the mass of agent relative to the mass of halon 1301 used to suppress the equivalent flame. Figure 3 summarizes the results using ambient temperature JP-8 (open bars), hot JP-8 (cross-hatch bars), and hot hydraulic fluid (solid bars). The agents in Figure 3 were arranged in order of increasing boiling points to better identify any possible relation between boiling point and agent performance. No obvious correlation was observed.

The mass fraction of agent relative to the total air plus agent rate of flow $(\beta)$ is often used to compare the performance of different fire suppressants. A flame suppression number can be defined on this basis as well, with the halon 1301 mass fraction used to normalize the results. The FSN computed on a mass flow basis can be seen in Figure 4. Grosshandler et 


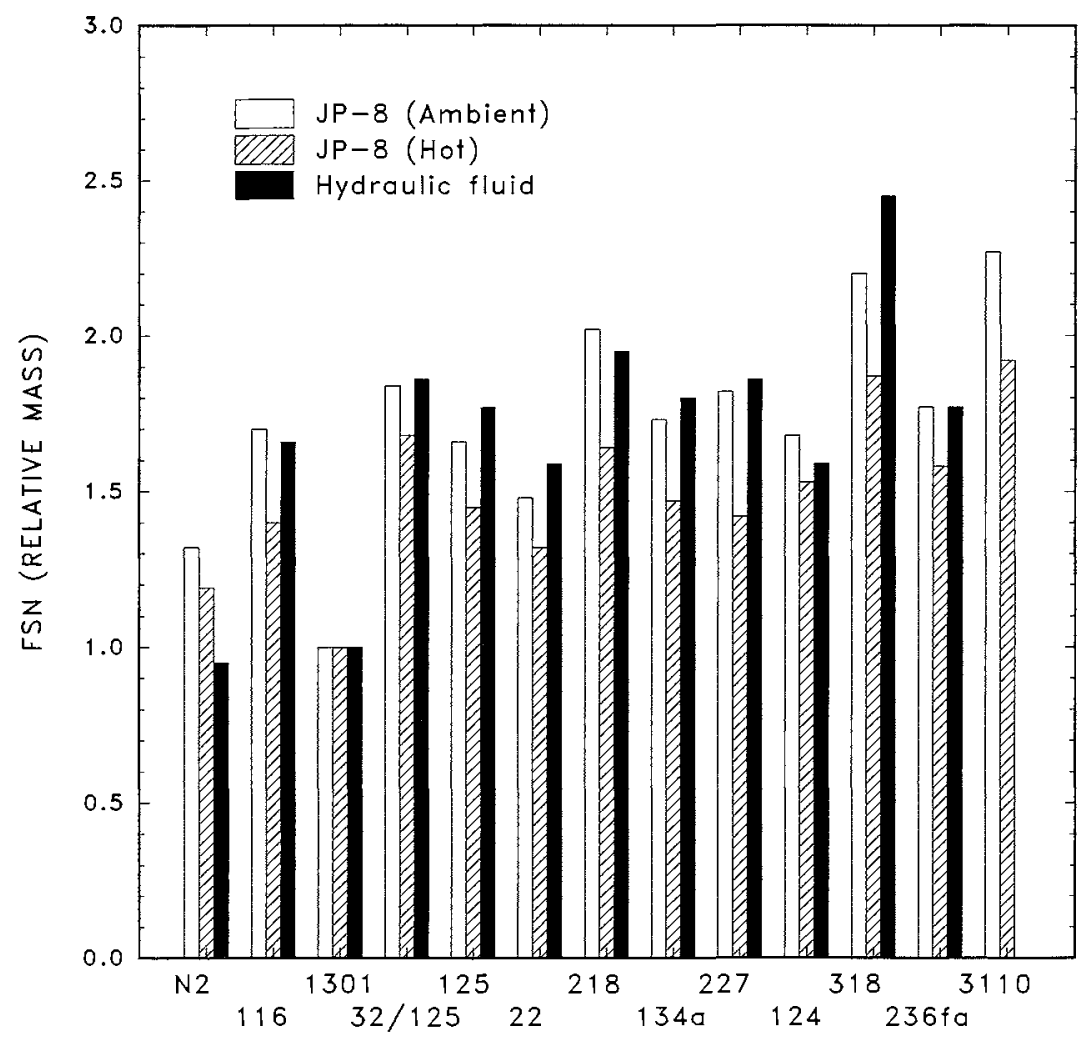

FIGURE 3 Agent flame suppression number relative to halon 1301 on a mass basis (open bars indicate ambient temperature JP8; cross-hatch bars indicate $150{ }^{\circ} \mathrm{C}$ air and hot JP8; solid bars indicate $120^{\circ} \mathrm{C}$ air and hot hydraulic fluid)

al. [4] compared the results of the ambient temperature JP-8 flame experiments to the results from a cup burner test [7]. The cup burner mass flow FSN was $2.0( \pm 0.15)$ for the various agents, which is 0.5 greater than the FSNs plotted in Figure 4. The implication is that it takes a significantly lower mass fraction of agent to extinguish the turbulent spray flame than the cup burner flame.

The cup burner was not operated at elevated temperatures, but measurements were made using ambient temperature hydraulic fluid. The same trend was observed when the cup and turbulent spray extinguishing mass fractions were compared: a measurable decrease in agent concentration is required for the turbulent spray flame (in spite of the fact that the higher reactant temperatures are expected to stabilize the spray flame, everything else being equal).

Minimizing the storage volume aboard the aircraft is as critical as minimizing the mass of agent. There are a number of densities which one could use to convert the mass of agent 


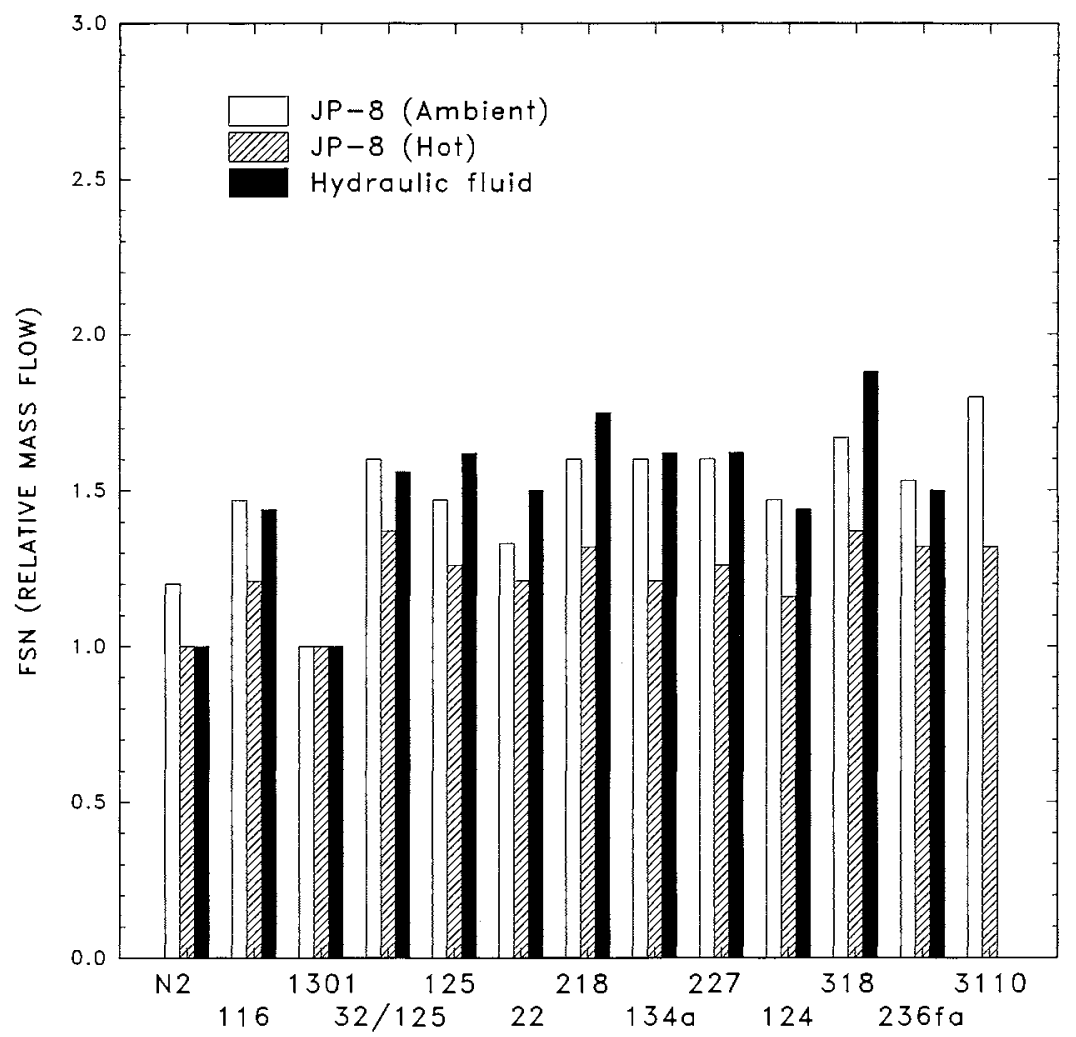

FIGURE 4 Agent flame suppression number computed on the mass flow basis (open bars indicate ambient temperature JP8; cross-hatch bars indicate $150^{\circ} \mathrm{C}$ air and hot JP8; solid bars indicate 120 ${ }^{\circ} \mathrm{C}$ air and hot hydraulic fluid)

required to the volume, including the dispersed gas density (which scales with molecular weight) and the density of the saturated liquid agent at ambient temperature. The latter density provides a logical conversion from the mass required to the storage volume because the conditions are close to those when the bottles are filled (assuming negligible solubility of the pressurizing gas). The volume factor is defined as the storage volume of the agent computed in the above manner normalized by the equivalent volume of halon 1301. Figure 5 displays the volume factors for the agents evaluated in this manner for the three test conditions. Nitrogen is off the scale because it does not liquify under typical bottle conditions. The FC-116 also rates poorly on volume factor because its critical temperature is less than ambient. The density of FC-116 in Figure 5 is calculated at $20^{\circ} \mathrm{C}$ and $4.1 \mathrm{MPa}$, a typical bottle pressure. The remainder of the agents have volume factors between 1.5 and 2.5 , depending on the agent, fuel and temperature. Of these, the HFC 32/125 mixture has the highest volume factor and HFC-227, HCFC-124 and HCFC-22 have the lowest. 


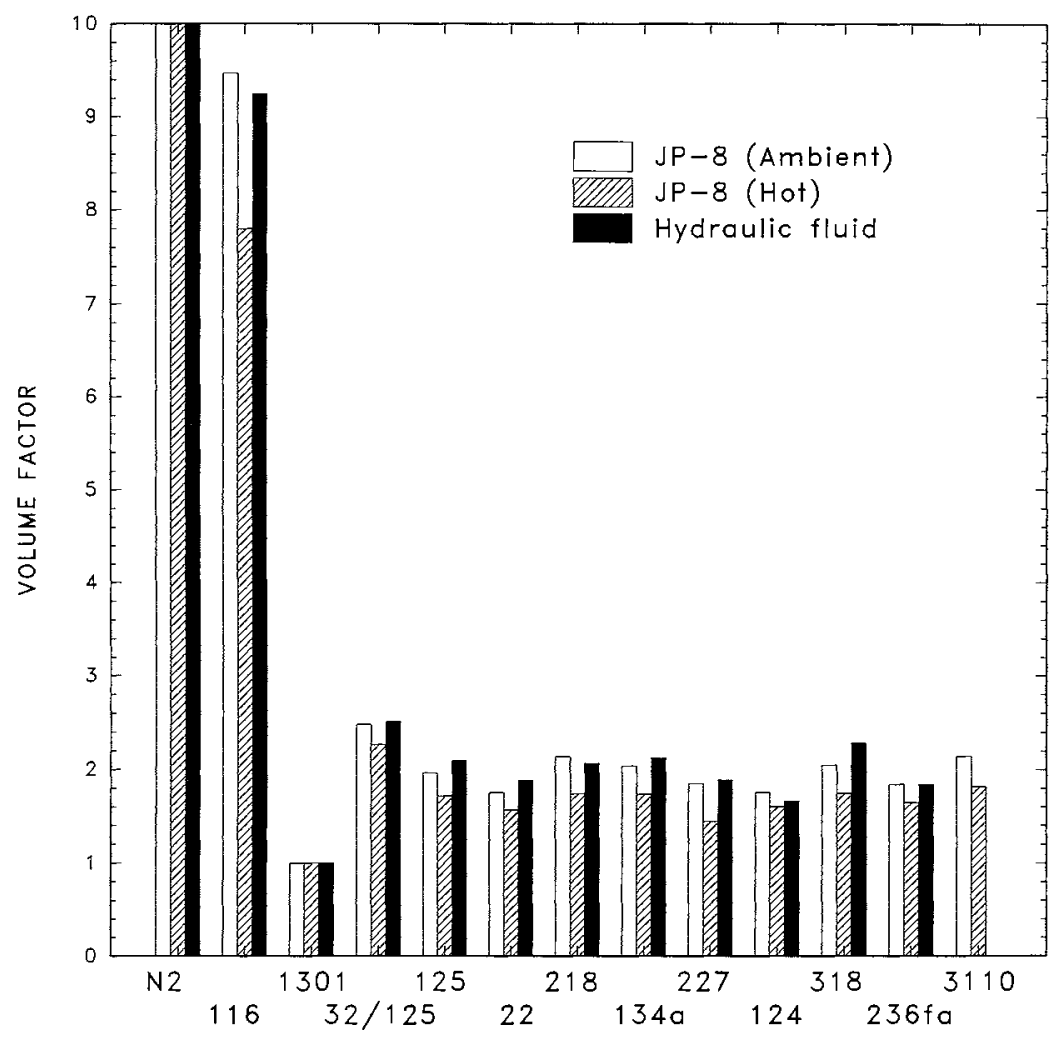

FIGURE 5 Agent relative storage volume or volume factor (open bars indicate ambient temperature JP8; cross-hatch bars indicate $150{ }^{\circ} \mathrm{C}$ air and hot JP8; solid bars indicate $120^{\circ} \mathrm{C}$ air and hot hydraulic fluid)

\section{SUMMARY AND CONCLUSIONS}

No statistically significant difference in agent performance was found between the room temperature JP-8 and hydraulic fluid flame testing, indicating little fuel effect. On the other hand, the majority of the agents required slightly more mass to extinguish the higher temperature JP-8 flame, indicating a small temperature effect. This trend is not completely unexpected since a higher enthalpy flame is likely to be more stable. However, the temperature effect did not dramatically alter the agent performance ranking, with the exception of $\mathrm{HFC}-125$.

The flame suppression number and the volume factor should both be considered when evaluating the performance of the different agents. Nitrogen was the best performer if one considers only the FSN; however it was the poorest performer on a volume factor basis. 
Agents HCFC-22 and HCFC-124 demonstrate good performance both on a mass and volumetric basis. Agents FC-31-10 and FC-318 were among the poorest performers on an FSN basis. All of the agents except nitrogen and FC-116 had volume factors between approximately 1.6 and 2.4 .

The results from this experiment need to be combined with other bench-scale experiments and full-scale testing before the best alternative for halon 1301 can be identified. Other considerations such as discharge properties, availability, toxicity, and price will play an important role in the selection process.

\section{ACKNOWLEDGEMENT}

The authors wish to acknowledge the U.S. Air Force, Army, and Navy and the Federal Aviation Administration for funding the Agent Screening for Halon 1301 Aviation Replacement program. The project was under the direction of Mr. Michael Bennett at the Flight Dynamics Laboratory, Vehicle Subsystems Division, Survivability Enhancement Branch, Wright Patterson AFB. The authors also wish to acknowledge Mr. James D. Allen for his assistance in the conversion of the experimental facility.

\section{REFERENCES}

1. Harrington, J.L., "The Halon Phaseout Speeds Up," NFPA Journal, 87: 2, 38-42, 1993.

2. Grosshandler, W.L., "Agent Screening for Halon 1301 Aviation Replacement", International CFC and Halon Alternatives Conference, 744-752, 1993.

3. Gann, R., "Agent/System Compatibility for Halon 1301 Aviation Replacement", International CFC and Halon Alternatives Conference, 753-760, 1993.

4. Grosshandler, W.L., Lowe, D., Rinkinen, W., and Presser, C., "A Turbulent Spray Burner for Assessing Halon Alternative Fire Suppressants," ASME Winter Annual Meeting, No. 93-WA/HT-23, 1993.

5. Taylor, B.N. and Kuyatt, C.E., "Guidelines for Evaluating and Expressing the uncertainty of NIST Measurement Results", NIST Technical Note 1297, 1993.

6. Van Wylen, G.J. and Sonntag, R.E., Fundamentals of Classical Thermodynamics, 2nd Ed., p. 400, John Wiley and Sons, New York, 1978.

7. Grosshandler, W.L., Gann, R.G. and Pitts, W.M., Editors, "Evaluation of Alternative In-flight Fire Suppressants for Full-scale Testing in Simulated Aircraft Engine Nacelles and Dry Bays," NIST Special Publication 861, 1994. 
